\title{
Development of optimal modes and mathematical models of energy performance of electric steelmaking production
}

\author{
H.T. Khakimov ${ }^{1 *}$, Z.M. Shayumova ${ }^{1,3}$, Z.Kh. Kurbanbaeva ${ }^{2}$, B.M. Khusanov ${ }^{1}$ \\ ${ }^{1}$ Tashkent State Technical University named after Islam Karimov, 100095, Uzbekistan, Tashkent, University St. 2A \\ ${ }^{2}$ Karakalpak State University, 230100, Uzbekistan, Nukus, Ch. Abdirov St.1 \\ ${ }^{3}$ Institute of Energy of the Academy of Sciences of the Republic of Uzbekistan, 700100, Tashkent city, Republic of Uzbekistan
}

\begin{abstract}
The article deals with the issues of determining the optimal modes of electric steelmaking production on the basis of analysis of the graph of changes in the average power and voltage of the arc furnace in one meltdown cycle. In addition, empirical equations for determining the flow rate and specific energy consumption during the operation of process equipment under normal conditions were obtained for the main equipment of the electric arc-furnace shop using the mathematical method.
\end{abstract}

In recent years, the consumption of electric energy of electric arc furnaces (EAF) increased sharply. With the continuous growth of the specific capacity and performance of electric furnaces the efficient uses of electric energy in smelting become great importance. In the article, the experience of operating EAF capacity of 100 tons of "Uzmetkombinat" is discussed [1-3].

Melt shop JSC "Uzmetkombinat" is a sophisticated technological complex of a number of interconnected units. The workshop is composed of the 100 - tons electric arc furnaces each with transformer capacity of $95 \mathrm{MV} \cdot \mathrm{A}$. The shop is IME-unit complex processing of steel (ICCO), which allows you to heat the metal and implement a large number of fine-tuning operations to the required quality steel in the ladle. In addition, the shop is equipped with varietal continuous casting machines (UNRS), each of which has four streams. The cross section blanks 250x320 mm.

Furnaces operate continuously. Prolonged shutdown occurs only when the furnace repair. Load of EAF is continuous-cyclic. Cyclical nature of the work is characterized by alternating heats with stops furnace drain metal filling the furnace and the filling mixture. There are three successive passing periods for melting steel: melting, oxidation, reduction [4-6].

Figure 1 shows a plot of the average power of the EAF-100 with transformer capacity of $95 \mathrm{MV} \cdot$ A for one smelting process cycle lasts about 60 minutes. The graph indicates the average load. In fact, the load has erratic dramatically alternating character, uneven in phases.

EAF load fluctuations, particularly reactive power fluctuations cause significant voltage fluctuations in the mains, which is the larger, the greater the power of the furnace transformer and a lower short-circuit power at the point of attachment of the arc furnace. Furthermore, EAF is the source of the higher harmonic components in the network and generates 3,5,7,11 etc. harmonics [7].

Selection of the main electrical parameters of arc furnaces is complex and ambiguous. Furnaces operate in various conditions, and they conducted processes can also be different. Key performance indicators are production and specific energy consumption depend on many factors give an analytical expression for optional values of these parameters, suitable for practical calculations and it is't represent possibility. Therefore, the definition of the main parameters of electric arc furnaces based on data from these operating systems and virtually experimental formulas derived on the basis of statistical data on existing furnaces [8-9].

In this workshop achieved an increase in productivity and reduction in specific energy consumption as well as reducing the time of melting by increasing the capacity of the furnace transformer with $45 \mathrm{MV} \cdot \mathrm{A} \cdot$ up to 95 MV A.

Furnace , EAF -100 "Uzmetkombinat" has the following parameters.

Corresponding author: ilider1987@yandex.com 
Table 1. Parameters of EAF -100 "Uzmetkombinat"

\begin{tabular}{|l|c|c|}
\hline \multicolumn{1}{|c|}{$\begin{array}{c}\text { EAF-100 } \\
\text { "Uzmetkombinat" }\end{array}$} & $\begin{array}{c}\text { Project } \\
\text { characteris } \\
\text { tics }\end{array}$ & $\begin{array}{c}\text { actual } \\
\text { character } \\
\text { istics }\end{array}$ \\
\hline Capacity, tons & 100 & 120 \\
\hline $\begin{array}{l}\text { The average weight of } \\
\text { melting, tons }\end{array}$ & 100 & 114 \\
\hline $\begin{array}{l}\text { The total duration of } \\
\text { melting, min }\end{array}$ & 90 & 60 \\
\hline $\begin{array}{l}\text { Performance of work } \\
\text { under the current, min }\end{array}$ & 60 & 46 \\
\hline Power transformer, MVA & $80-600$ & $250-750$ \\
\hline $\begin{array}{l}\text { Limits secondary voltage, } \\
\text { V }\end{array}$ & 610 & 610 \\
\hline Diameter, mm & $2 \times 20$ & $4 \times 3,5$ \\
\hline $\begin{array}{l}\text { Nozzles of natural gas, } \\
\text { MV }\end{array}$ & & \\
\hline
\end{tabular}

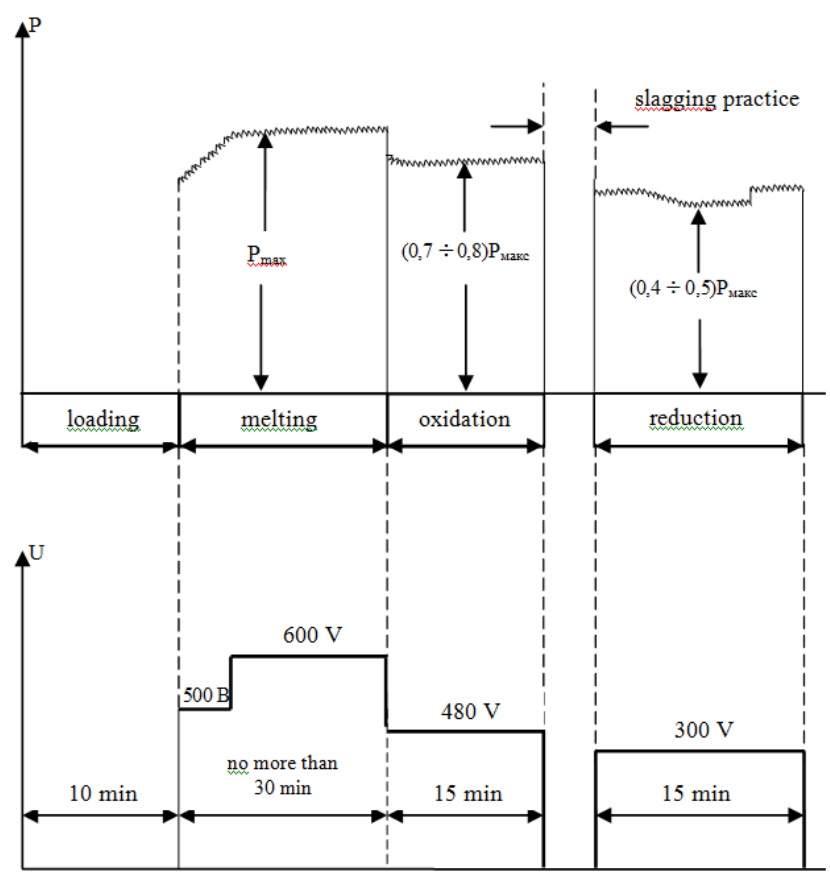

Fig.1. Schedule changes in the average power and voltage of arc furnace EAF for one technological cycle of melting

Conversion of electrical energy into heat is carried out in these arc furnaces in electric arcs, burning in the furnace between the electrodes and metal covered with slag. In EAF electric arc burn on metal and represent the load, circuit is connected on $\mathrm{Y}$ to the location of the zero point or a strong charge, either liquid metal.

Efficiency of power consumption EAF is provided with optimal electric mode, ie, when the electric arc furnace operates with the highest performance at the lowest power consumption. Both of these conditions do not coincide with the same operating current. However, there is a relatively small range of operating currents, within which one can get close to the optimum values for both the main indicators [10].
For determining the energy saving mode, the optimal active power is set in furnace installation.

Changing the active power is achieved by changing the operating voltage and the alternation of continuous operation at different voltages.

The following Table 2 shows the actual value of specific energy consumption by type of equipment shop EAFP for 2018.

Table 2. The actual value of specific energy consumption by type of equipment shop EAFP for 2018

\begin{tabular}{|r|l|c|c|c|c|}
\hline \multirow{2}{*}{ № } & \multirow{2}{*}{ N 2018 } & \multicolumn{3}{|c|}{ The specific energy consumption, } \\
\cline { 3 - 6 } & & EAF & $\begin{array}{c}\text { (IC } \\
\text { CO) }\end{array}$ & $\begin{array}{l}\text { UNR } \\
\text { S }\end{array}$ & $\begin{array}{c}\text { Total } \\
\text { EAFP }\end{array}$ \\
\hline 1 & January & 363,4 & 35,8 & 27,2 & 426,4 \\
\hline 2 & February & 354,9 & 28,5 & 26,6 & 410 \\
\hline 3 & March & 358 & 31,8 & 26 & 415,8 \\
\hline 4 & April & 361,3 & 28,6 & 25,7 & 415,6 \\
\hline 5 & May & 360,1 & 28,3 & 23 & 411,4 \\
\hline 6 & June & 357,4 & 27,5 & 24,6 & 409,5 \\
\hline 7 & July & 355,8 & 30,4 & 23,6 & 409,8 \\
\hline 8 & August & 360 & 29,5 & 24,9 & 414,4 \\
\hline 9 & September & 358,5 & 28,6 & 25,1 & 412,2 \\
\hline 10 & October & 351,6 & 28,5 & 26,9 & 407 \\
\hline 11 & November & 352,2 & 25,6 & 25,8 & 403,6 \\
\hline 12 & December & 369,2 & 22,3 & 27,8 & 419,3 \\
\hline Average Months & $\mathbf{3 5 9}$ & $\mathbf{2 8 , 8}$ & $\mathbf{2 5 , 6}$ & $\mathbf{4 1 2 , 9}$ \\
\hline
\end{tabular}

The table shows that $87 \%$ of electricity consumption is used in the furnace EAF, $7 \%$ in the ICCO, and $6 \%$ in the continuous caster.

Based on the above data on the energy indicators of main equipment of ESMS by using empirical equations are mathematical methods to determine the flow rate and specific energy consumption during operation of technological equipment under normal conditions.

Equipment - EAF

$$
W_{E A F}=0,335 \cdot \Pi_{E A F}+1844, \mathrm{~kW} \cdot \mathrm{h} / \text { month }
$$

$$
e_{E A F}=0,335+\frac{1844}{\Pi_{E A F}}, \mathrm{~kW} \cdot \mathrm{h} / \mathrm{t}
$$

Equipment - ICCO

$$
\begin{aligned}
& W_{I C C O}=0,019 \cdot \Pi_{I C C O}+619, \mathrm{~kW} \cdot \mathrm{h} / \text { month } \\
& e_{I C C O}=0,019+\frac{619}{\Pi_{I C C O}}, \quad \mathrm{~kW} \cdot \mathrm{h} / \mathrm{t}
\end{aligned}
$$

Equipment - UNRS 


$$
\begin{aligned}
& W_{U N R S}=0,019 \cdot \Pi_{U N R S}+371,45, \mathrm{~kW} \cdot \mathrm{h} / \text { month } \\
& e_{U N R S}=0,019+\frac{371,45}{\Pi_{U N R S}}, \mathrm{~kW} \cdot \mathrm{h} / \mathrm{t} \\
& \quad \text { For lime-burning site }-\mathrm{YOW} \\
& W_{\text {YOW }}=0,0208 \cdot \Pi_{\text {YOW }}+55,457, \mathrm{~kW} \cdot \mathrm{h} / \text { month } \\
& e_{\text {YOW }}=0,0208+\frac{55,457}{\Pi_{Y O W}}, \mathrm{~kW} \cdot \mathrm{h} / \mathrm{t}
\end{aligned}
$$

The resulting mathematical models of flow and the specific energy consumption for production equipment EAFP shop allow a sufficient accuracy for practical purpose to analyze and predict the energy performance and evaluate the efficiency of their work.

Thus, analysis, optimum energy performance of electric arc furnaces leads to the following conclusions:

1.Maintain at each stage of steelmaking optimal modes EAF-100 minimizes the duration of melting and power consumption.

2. Standards of electricity consumption in the smelting of various steel grades obtained during the examination EAF - 100 .

3. Statistics by sampling the energy performance EAF -100 include information about melting, corresponding to the normal conditions of their conduct.

\section{References}

1. B.Kudrin, Electrician, 9, 35-45 (2003).

2. B.Kudrin, Ind. Ener., 6, 22-25 (2006).

3. V.Klyunya, FET, 238 (2006).

4. L.Koptsev, A.Koptsev, Ind. Ener., 1, 18-23 (2011).

5. A.Grinev, Ind. Ener., 3, 19-22 (2012).

6. L.Kazarinova, T.Barbasova, O.Kolesnikova, A.Zakharova, CTME, 14, 5-11 (2014).

7. M.Bazaar, K.Shetty, NPTA, 583 (1982).

8. I.Rakhmonov Technical science and innovation: Vol. 2018 Iss. 1 , Article 10. (2018)

9. F.Hoshimov, .Rahmonov, AJTNS, 3-4, 52-55 (2015).

10. F. Khoshimov, I.Rakhmonov, Technical science and innovation: Vol. 2018 : Iss. 1, Article 9. (2018) 